\title{
The Impact of COVID-19 on Neuro-Ophthalmology Office Visits and Adoption of
} Telemedicine Services

\author{
Heather E. Moss, MD, PhD ${ }^{1,2 *}$ \\ Melissa W. Ko, MD ${ }^{3,4,5 *}$ \\ Devin D. Mackay, $\mathrm{MD}^{3,4,5}$ \\ Divya Chauhan, $\mathrm{MD}^{3}$ \\ Karen Guadalupe Gutierrez ${ }^{1}$ \\ Natacha C. Villegas, MD $^{1}$ \\ Kevin E. Lai, MD ${ }^{5,6,7}$
}

${ }^{1}$ Department of Ophthalmology, Stanford University, Palo Alto, CA, USA

${ }^{2}$ Department of Neurology \& Neurological Sciences, Stanford University, Palo Alto, CA, USA

${ }^{3}$ Department of Neurology, Indiana University School of Medicine, Indianapolis, IN, USA

${ }^{4}$ Department of Neurosurgery, Indiana University School of Medicine, Indianapolis, IN, USA

${ }^{5}$ Department of Ophthalmology, Indiana University School of Medicine, Indianapolis, IN, USA

${ }^{6}$ Ophthalmology Service, Richard L. Roudebush Veterans Administration Medical Center, Indianapolis, IN, USA

${ }^{7}$ Neuro-Ophthalmology Section, Midwest Eye Institute, Carmel, IN, USA

*These authors contributed equally to this paper.

Running title: COVID-19 impact on practice

Keywords: pandemic, telehealth, telemedicine, neuro-ophthalmology, COVID-19

Corresponding author:

Kevin E. Lai

Midwest Eye Institute

10300 N. Illinois St., Suite 1000, Carmel, IN 46290

kevin.e.lai@gmail.com

(w) 317-805-2240

(f) $317-527-4708$

Conflict of interest: The authors report no conflicts of interest

Funding: Research to Prevent Blindness unrestricted grant to the Stanford Department of Ophthalmology, NIH P30 086277

This is the author's manuscript of the article published in final edited form as:

Moss, H. E., Ko, M. W., MacKay, D. D., Chauhan, D., Guadalupe Gutierrez, K., Villegas, N. C., \& Lai, K. E. (2021). The Impact of COVID-19 on Neuro-Ophthalmology Office Vists and Adoption of Telemedicine Services.pdf. Journal of Neuro-Ophthalmology. 
Background: The COVID-19 public health emergency (PHE) has significantly changed medical practice in the U.S., including an increase in the utilization of telemedicine. Here, we characterize change in neuro-ophthalmic care delivery during the early COVID-19 PHE, including a comparison of care delivered via telemedicine and in office.

Methods: Neuro-ophthalmology outpatient encounters from three practices in the United States (four providers) were studied during the early COVID-19 PHE (March 15, 2020-June 15, 2020) and during the same dates one year prior. For unique patient visits, patient demographics, visit types, visit format, and diagnosis were compared between years and between synchronous telehealth and in-office formats for 2020 .

Results: There were 1276 encounters for 1167 patients. There were 30\% fewer unique patient visits in 2020 vs. 2019 (477 vs. 670) and 55\% fewer in office visits (299 vs. 670). Compared to 2019, encounters in 2020 were more likely to be established, to occur via telemedicine and relate to an efferent diagnosis. In 2020, synchronous telehealth visits were more likely to be established compared with in-office encounters.

Conclusions: In the practices studied, a lower volume of neuro-ophthalmic care was delivered during the early COVID-19 public health emergency than in the same period in 2019. The type of care shifted toward established patients with efferent diagnoses and the modality of care shifted toward telemedicine. 


\section{Introduction}

The COVID-19 pandemic indelibly altered medical practice worldwide. In order to maintain access to care for high-risk patients and decrease the risk of exposure to the SARS-CoV-2 virus, telemedicine, previously reserved for limited populations, was broadly adopted to meet these demands.(1-3) Neuro-ophthalmologists, like many specialties, had to rapidly develop new protocols and consider what conditions may be appropriate for telemedicine, and which cases warranted an in-person visit due to increased risks in order to continue delivery of care. $(4,5)$

In a survey of neuro-ophthalmologists in active independent practice, the COVID-19 public health emergency (PHE) was associated with a significant global increase of adoption of video and other telemedicine services for neuro-ophthalmic care despite barriers of data quality and infrastructure. A majority of users indicated video visits were most helpful for efferent problems and afferent problems with prior ancillary testing.(6) Other reviews have noted an important role of synchronous telemedicine for patient triage.(7) However, data on patient volumes in neuroophthalmology has not been reported in these and other studies, so the impact on patient care has not been assessed.

The primary purpose of this study was to evaluate the impact of COVID-19 on outpatient neuroophthalmic care by comparing clinical visits in three practices (four practitioners) during the early PHE with a control period from the same time in 2019. A secondary purpose was to compare telemedicine and in-person visits during the PHE.

\section{Methods}


A multicenter retrospective chart review was performed on all neuro-ophthalmology outpatient encounters by four providers at three institutions, one private-practice (Circle City NeuroOphthalmology at Midwest Eye Institute) and two academic centers (Indiana University and Stanford University), between March 15, 2020 and June 15, 2020. This date range was selected to capture the first 3 months of the COVID-19 PHE in the U.S. Outpatient encounters for three of the providers between March 15, 2019 and June 15, 2019 were used as a comparison. Inclusion criteria for encounters were completed visits with a participating neuro-ophthalmologist for a neuro-ophthalmic appointment during one of the two time periods. Exclusion criteria were general ophthalmology, general neurology or surgical (pre-operative or post-operative) visits. The study was deemed exempt by the Indiana University Institutional Review Board and was approved with waiver of informed consent by the Stanford research compliance office.

Data was extracted at the encounter level. Encounter variables included site, year $(2019,2020)$ visit type (new, return, study), visit format (in-office, synchronous video and audio, synchronous audio only, interprofessional consult), visit number for a given patient in a given year, primary diagnosis ICD-10 code which was classified as afferent, efferent or other. Patient variables either extracted from or calculated based on the medical record included age at time of visit (difference between encounter date and birth date), gender, type of insurance (Medicare, Medicaid/Other Government, Commercial, Self-Pay), and distance from the patient's address to the examining provider's clinic address calculated using the shortest driving distance on Google maps. Each site collected data separately. De-identified data was merged for analysis.

\section{Statistical Analysis}

Data analysis considered first encounters for each patient during each time period studied. Subsequent encounters were excluded from analysis. The primary comparison was between 2019 and 2020 encounters. Encounter and patient variables were compared between years 
using a chi-squared test for categorical variables, t-test for independent samples for continuous normally distributed variables and Mann-Whitney $U$ test for continuous variables with skewed distribution.

The secondary comparison was between 2020 synchronous telemedicine encounters (video + audio, audio only) and in-office visits. Similar to the primary analysis only first visits for each patient were included. Statistical comparisons were performed as for the primary comparison. Statistical analysis was performed using SPSS V26 (IBM Inc.).

\section{Results}

$$
\text { M Inc.). }
$$

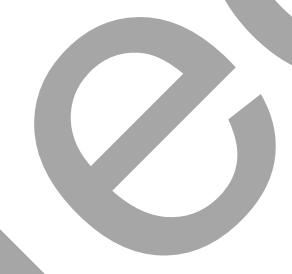

1276 encounters for 1167 patients were extracted. They were approximately evenly divided between Indiana-private practice, Indiana-academic and California-academic ( $n=357,457,462$ respectively). Among first visits during the study periods, 741 were new patient encounters, 422 were established patient encounters and 4 were study visits. 969 (83\%) of visits were in-office, 179 (15.3\%) were synchronous video + audio, 15 (1.3\%) were synchronous audio only and 4 (0.3\%) were asynchronous interprofessional consults. Visit diagnoses were afferent for 722 (62\%) of first encounters, efferent for 267 (22.9\%) and other for 176 (15.1\%). The most common diagnoses seen were papilledema/pseudotumor cerebri $(174,13.6 \%)$, diplopia $(122,9.56 \%)$, and visual field defect (121, 9.48\%). Diagnosis was missing for 2 encounters.

Unique patients ranged in age from 2-95 years old, were 64.5\% female and lived 1 to 2968 miles from the outpatient clinic. The majority of patients had commercial insurance (50.9\%), while $28.2 \%$ had Medicare, $18.6 \%$ had other government insurance (Medicaid or Veterans' Affairs) and 2.2\% were self-pay. Residential address could not be obtained for 53 patients. Insurance status was missing for 5 patients. 
2019 vs. 2020

682 encounters occurred for 670 patients between 3/15/19 and 6/15/19 and 594 encounters occurred for 497 patients between 3/15/20 and 6/15/20. The proportion of unique patient visits did not differ across sites, with all sites seeing fewer visits in 2020 vs. 2019 ( $p=0.12$, chisquare). Although 2020 saw a shift in encounter distributions, the majority of visits remained inoffice and for afferent diagnoses. Compared with those in 2019 , unique patient encounters in 2020 were more likely to be established, to occur via telemedicine, and to relate to an efferent diagnosis (Table 1). A 2019 to 2020 comparison stratified by site is provided in the supplemental data (Tables E1-E3).

In 2019, the most common diagnoses seen in new patients were visual field defects, other, diplopia, papilledema, optic atrophy, and subjective visual disturbances; in 2020, the most common diagnoses seen in new patients were diplopia, visual field defect, subjective visual disturbances, papilledema, and sudden vision loss (Figure 1). In both 2019 and 2020 papilledema/pseudotumor cerebri was the most commonly seen diagnosis (Table 2).

2020 Office vs. 2020 Telehealth

Between 3/15/20 and 6/15/20 (early COVID-19 PHE), unique patients had 299 in-office visits and 194 synchronous telehealth visits in the practices studied. Synchronous telehealth visits were less likely to be new patient encounters (Table 3). A 2020 in-office vs. telehealth comparison stratified by site is provided in supplemental data (Tables E4-E6).

\section{Conclusions}


This study builds on a survey of telemedicine adoption by neuro-ophthalmologists during the COVID-19 PHE(6) and multiple expert commentaries of application of telemedicine to deliver neuro-ophthalmic care $(4,5,7-10)$ by quantifying the amount and type of care provided by a convenience sample of neuro-ophthalmologists during this unprecedented time. This study also contributes to the broader literature on medical care during the COVID-19 PHE. Strengths of the study are the inclusion of all patients seen by the included providers, inclusion of academic and non-academic practices in multiple states, and comparison with a control period one year prior.

Approximately $30 \%$ fewer unique patients were seen in the early COVID time period studied in 2020 than 2019 with 55\% fewer in-office visits. This is despite one of the providers only contributing patients to the 2020 sample and less work and personal travel by all the providers in 2020 compared to 2019. This aligns with what has been reported in the U.S. across medical specialties with the drop-off in all visits and in-person visits during the early COVID-19 PHE.(11) Many factors may have contributed to this decrease, including changes to supply factors (offices closed, decreased staff, social distancing, policy limiting scheduling to urgent visits, efforts to preserve personal protective equipment, increased home commitments of providers) and demand factors (decreased referrals, patient voluntary deferral, office-recommended deferral).

Differences in early COVID 2020 patient visits when compared with 2019 included an increase in the proportion of established patient visits, increase in the proportion of efferent diagnoses, and decrease in the proportion of other (non-afferent and non-efferent) diagnoses. The mostcommonly seen diagnoses also changed for new consults between 2019 and 2020, suggesting a shift away from less urgent conditions (visual field defect, other, optic atrophy) towards more urgently-perceived conditions (diplopia, papilledema, sudden vision loss) during the PHE. The increase in utilization of telehealth modalities was particularly striking as telemedicine modalities were not utilized by any of the three sites in 2019 . This adoption was enabled by a combination 
of institutional technological support at the two academic institutions, changes in regulation and reimbursement, and increased interest by providers and patients to accommodate lockdown measures during the COVID-19 PHE. Similar changes in the modality and volume of care were observed in primary care. A comparison from the second calendar quarters of 2018 and 2019 to the second calendar quarter of 2020 in primary care showed a $21.4 \%$ decrease in the total number of primary care healthcare encounters. Office-based visits decreased by $50.2 \%$ in quarter 2 of 2020 compared with the same quarter in 2018 and 2019. 1.1\% of visits were telemedicine-based in 2018 and 2019, compared with 35.3\% in the second quarter of 2020.(12) Pre-pandemic, telemedicine adoption within neurology was well established for some neurological subspecialties including stroke,(13) but in ophthalmology was limited to remote review of images.(14) The COVID-19 pandemic led to rapid, near universal adoption in many medical disciplines with neurology being a leader and ophthalmology having low uptake.(15) Neuro-ophthalmology straddles the two fields, sharing telemedicine benefits with neurology including thorough history, external examination, and record review, but also suffering the drawbacks of the inability to perform an ophthalmoscopic exam that has limited uptake of telemedicine in ophthalmology beyond neuro-ophthalmology, oculoplastics and pediatric ophthalmology.(16)

Although the majority of unique patient encounters were delivered via in-office care during early COVID-19 PHE in 2020, almost 40\% were delivered via telemedicine. Consistent with opinion surveys of the suitability of telehealth visits for neuro-ophthalmic disorders, efferent conditions were more likely to be seen via telemedicine while afferent conditions were less likely to be seen via telemedicine, although this difference did not reach statistical significance. However, the majority of telemedicine patient encounters were for afferent diagnoses reinforcing the role of telemedicine for check-in and triage during the pandemic.(7) New visit encounters, which 
formed the majority of neuro-ophthalmic encounters in 2019 and 2020, were less likely to occur via telemedicine. This may reflect new referrals during the PHE being for urgent matters and triaged to in person and both patient and provider discomfort with telemedicine as a format for the initial encounter.

Anecdotally, the authors feel that telemedicine formats enabled them to increase access to care beyond what would have been possible in 2020 due to governmental and institutional restrictions. The benefit of increasing patient access to care offered by the telemedicine format suggests a potential role for addressing the demand:supply mismatch for neuro-ophthalmology outside of a pandemic.(17-21) This is particularly relevant as the negative outcomes to delayed neuro-ophthalmic care are becoming quantified.(22)

There are some limitations to this study. Though the sample size of visits is large, the number of practices studied (4 practitioners in 3 settings) is small with only 2 geographic regions considered. The use of primary diagnosis as the reason for visit does not capture subtleties of each patient's presentation and the type of care provided. One provider did not see patients at any of the study sites in 2019 and therefore only contributed patients in 2020 .

In conclusion, medical care is just one of many services that changed dramatically during the COVID-19 PHE. In this study we demonstrate the overall reduction in neuro-ophthalmic care delivered during the early COVID-19 PHE, with a shift from new consults to established visits compared to the same time period one year prior. Adoption of telemedicine modalities shifted some care away from in-office settings in 2019 , though the majority of neuro-ophthalmology care was still provided in office. 


\section{References}

1. Mann DM, Chen J, Chunara R, Testa PA, Nov O. COVID-19 transforms health care through telemedicine: Evidence from the field. J Am Med Inform Assoc. 2020;27:11321135.

2. Wosik J, Fudim M, Cameron B, Gellad ZF, Cho A, Phinney D, Curtis S, Roman M, Poon EG, Ferranti J, Katz JN, Tcheng J. Telehealth transformation: COVID-19 and the rise of virtual care. J Am Med Inform Assoc. 2020;27:957-962.

3. Kanamori H, Weber DJ, Rutala WA. The role of the healthcare surface environment in SARS-CoV-2 transmission and potential control measures. Clin Infect Dis. 2020.

4. Grossman SN, Calix R, Tow S, Odel JG, Sun LD, Balcer LJ, Galetta SL, Rucker JC. Neuro-ophthalmology in the Era of COVID-19: Future Implications of a Public Health Crisis. Ophthalmology. 2020;127:e72-e74.

5. Lai KE, Ko MW, Rucker JC, Odel JG, Sun LD, Winges KM, Ghosh A, Bindiganavile SH, Bhat N, Wendt SP, Scharf JM, Dinkin MJ, Rasool N, Galetta SL, Lee AG. Tele-NeuroOphthalmology During the Age of COVID-19. J Neuroophthalmol. 2020;40:292-304.

6. Moss HE, Lai KE, Ko MW. Survey of Telehealth Adoption by Neuro-ophthalmologists During the COVID-19 Pandemic: Benefits, Barriers, and Utility. J Neuroophthalmol. 2020;40:346-355.

7. Liu YA, Ko MW, Moss HE. Telemedicine for neuro-ophthalmology: challenges and opportunities. Curr Opin Neurol. 2021;34:61-66.

8. Calix R, Grossman SN, Rasool N, Small L, Cho C, Galetta SL, Balcer LJ, Rucker JC. Practical Approach to the Tele-Neuro-Ophthalmology and Neuro-Otology Visits: Instructional Videos. J Neuroophthalmol. 2021;41:10-12.

9. Ko MW, Busis NA. Tele-Neuro-Ophthalmology: Vision for 20/20 and Beyond. J Neuroophthalmol. 2020;40:378-384. 
10. Ko M, Lai K, Mackay D. Teleneuro-ophthalmology. Practical Neurology [Internet]. 2020 March 30, 2021. Available from: https://practicalneurology.com/articles/2020june/teleneuro-ophthalmology.

11. Mehrotra A, Chernew C, Linetsky D, Hatch H, Cutler D, Schneider E. The impact of the COVID-19 pandemic on outpatient visits: a rebound emerges. To the Point (blog), Commonwealth Fund [Internet]. 2020. Available from: https://www.commonwealthfund.org/publications/2020/apr/impact-covid-19-outpatientvisits.

12. Alexander GC, Tajanlangit M, Heyward J, Mansour O, Qato DM, Stafford RS. Use and Content of Primary Care Office-Based vs Telemedicine Care Visits During the COVID-19 Pandemic in the US. JAMA Netw Open. 2020;3:e2021476.

13. Silva GS, Farrell S, Shandra E, Viswanathan A, Schwamm LH. The status of telestroke in the United States: a survey of currently active stroke telemedicine programs. Stroke. 2012;43:2078-2085.

14. Rathi S, Tsui E, Mehta N, Zahid S, Schuman JS. The Current State of Teleophthalmology in the United States. Ophthalmology. 2017;124:1729-1734.

15. Mehrotra A, Chernew C, Linetsky D, Hatch H, Cutler D, Schneider E. The impact of COVID-19 on outpatient visits in 2020: visits remained stable, despite a late surge in cases. Commonwealth Fund [Internet]. 2021. Available from:

https://www.commonwealthfund.org/publications/2021/feb/impact-covid-19-outpatientvisits-2020-visits-stable-despite-late-surge.

16. Patel S, Hamdan S, Donahue S. Optimising telemedicine in ophthalmology during the COVID-19 pandemic. J Telemed Telecare. 2020:1357633×20949796.

17. DeBusk A, Subramanian PS, Scannell Bryan M, Moster ML, Calvert PC, Frohman LP. Mismatch in Supply and Demand for Neuro-Ophthalmic Care. J Neuroophthalmol. 2021. 
18. Frohman LP. How can we assure that neuro-ophthalmology will survive? Ophthalmology. 2005;112:741-743.

19. Frohman LP. The human resource crisis in neuro-ophthalmology. J Neuroophthalmol. 2008;28:231-234.

20. Frohman LP. Neuro-Ophthalmology: Transitioning From Old to New Models of Health Care Delivery. J Neuroophthalmol. 2017;37:206-209.

21. Stunkel L, Mackay DD, Bruce BB, Newman NJ, Biousse V. Referral Patterns in NeuroOphthalmology. J Neuroophthalmol. 2020;40:485-493.

22. Stunkel L, Sharma RA, Mackay DD, Wilson B, Van Stavern GP, Newman NJ, Biousse V. Patient Harm due to Diagnostic Error of Neuro-Ophthalmologic Conditions. Ophthalmology. 2021. 


\section{Figure Legend}

Figure 1: Number of patients with common neuro-ophthalmic diagnoses seen pre-COVID (March 15, 2019-June 15, 2019) and early-COVID (March 15, 2020-June 15, 2020) according to visit type (new, established).

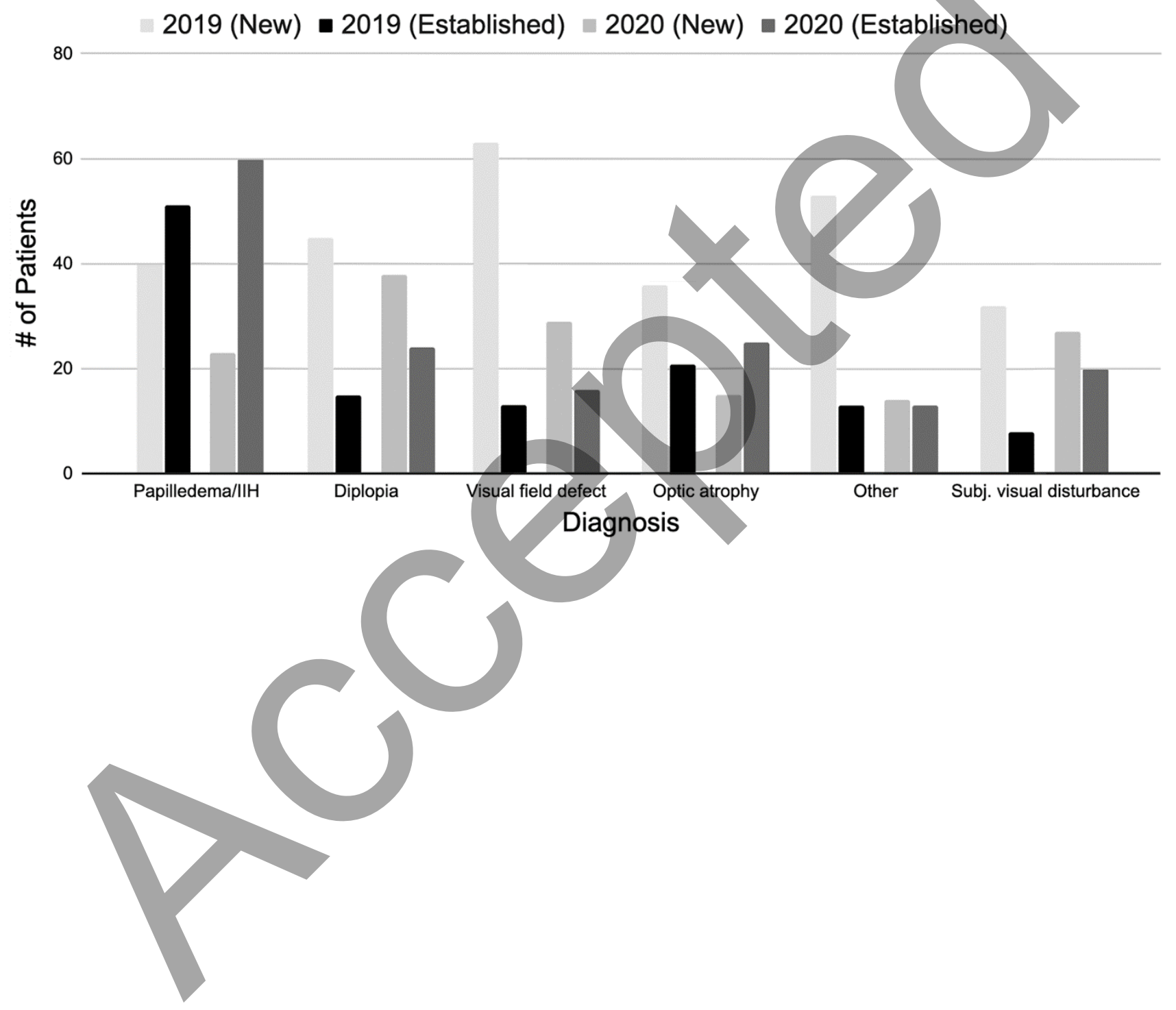


Table 1: Comparison between unique patient encounters between 2019 and 2020 (March 15June 15)

\begin{tabular}{|c|c|c|c|}
\hline & $\begin{array}{l}2019 \\
(n=670)\end{array}$ & $\begin{array}{l}2020 \\
(n=467)\end{array}$ & p-value \\
\hline Age in years (mean $+/-S D$ ) & $51.3+/-18.9$ & $50.2+/-18.9$ & $\mathrm{p}=0.32$ (t-test) \\
\hline Female gender (n (\%)) & $443(66.1 \%)$ & $310(62.4 \%)$ & $p=0.19(C S)$ \\
\hline $\begin{array}{l}\text { Distance in miles } \\
\text { (median, range) }\end{array}$ & $35(1.2-2968)$ & $28.5(1-461)$ & $06(\mathrm{MW})$ \\
\hline $\begin{array}{l}\text { Insurance } \\
\text { Medicare } \\
\text { Commercial } \\
\text { Other government } \\
\text { Self-Pay }\end{array}$ & $\begin{array}{l}193(29.0 \%) \\
330(49.6 \%) \\
130(18.5 \%) \\
12(1.8 \%)\end{array}$ & $\begin{array}{l}135(27.2 \%) \\
262(52.7 \%) \\
86(17.3 \%) \\
14(2.8 \%)\end{array}$ & 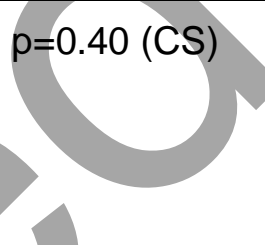 \\
\hline $\begin{array}{l}\text { Visit type } \\
\text { New } \\
\text { Established } \\
\text { Study }\end{array}$ & $\begin{array}{l}445(60.1 \%) \\
221(33.0 \%) \\
4(0.6 \%)\end{array}$ & $\begin{array}{l}201(47.6 \%) \\
296(59.6 \%) \\
0(0 \%)\end{array}$ & $(\mathrm{CS})$ \\
\hline $\begin{array}{l}\text { Visit format } \\
\text { In-office } \\
\text { Video + audio } \\
\text { Audio only } \\
\text { Interprofessional }\end{array}$ & $\begin{array}{l}670(100 \%) \\
0 \\
0 \\
0\end{array}$ & $\begin{array}{l}299(60.2 \%) \\
179(36.0 \%) \\
15(3.0 \%) \\
4(0.8 \%)\end{array}$ & $P<0.0005$ (CS) \\
\hline $\begin{array}{l}\text { Diagnosis } \\
\text { Afferent } \\
\text { Efferent } \\
\text { Other }\end{array}$ & $\begin{array}{l}417(62.3 \%) \\
137(20.5 \%) \\
115(17.2 \%)\end{array}$ & $\begin{array}{l}305(61.5 \%) \\
130(26.2 \%) \\
61(12.3 \%)\end{array}$ & $p=0.01(C S)$ \\
\hline
\end{tabular}

CS = Chi-Squared test; MW = Mann-Whitney U test 
Table 2: Most common diagnoses in pre-COVID (March 15-June 15, 2019) and early-COVID (March 15-June 15, 2020) periods according to visit type

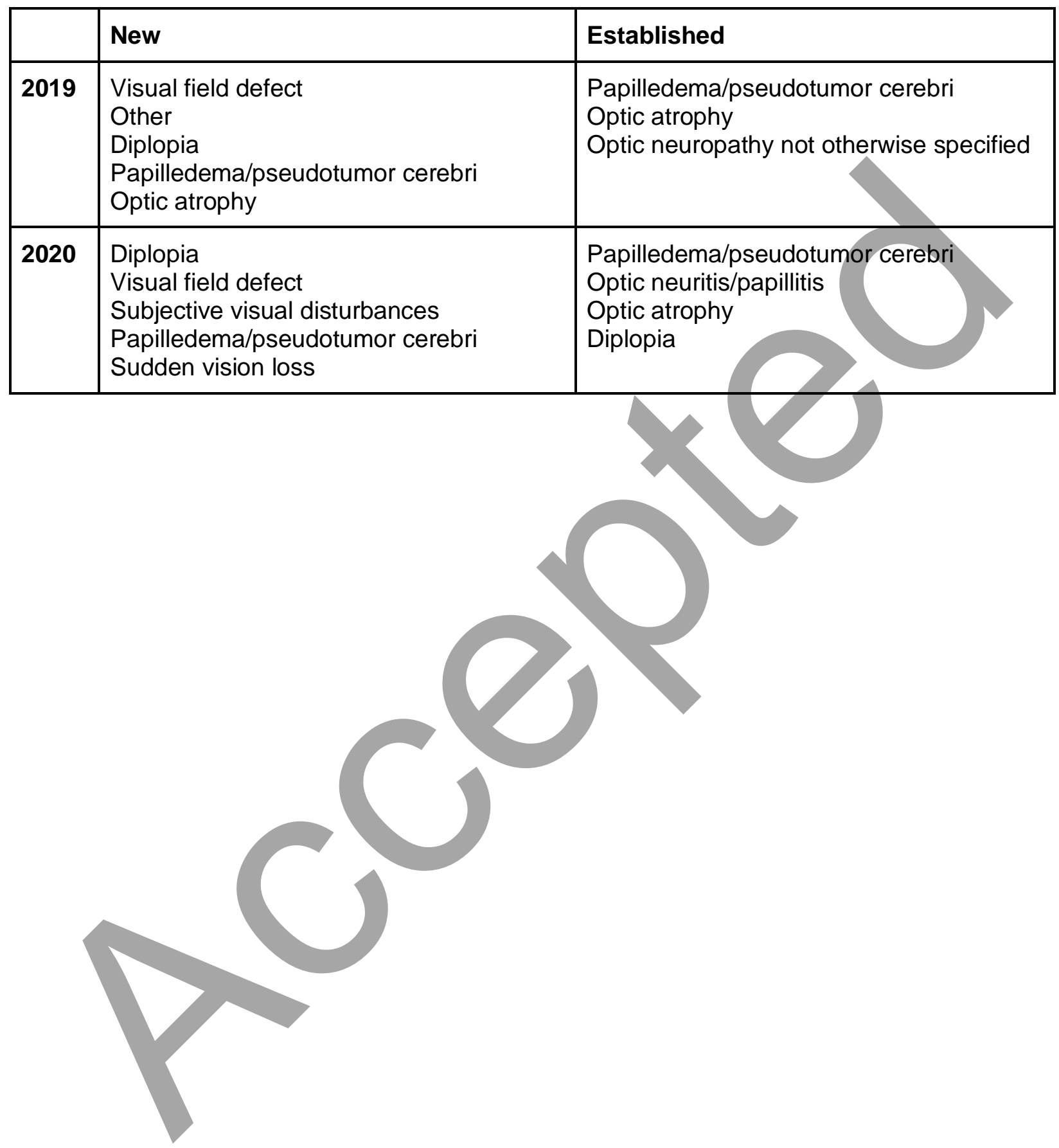


Table 3: Comparison between unique patient encounters 3/15/20-6/15/20 according to visit format.

\begin{tabular}{|c|c|c|c|}
\hline & $\begin{array}{l}\text { In-Office visit } \\
(n=299)\end{array}$ & $\begin{array}{l}\text { Synchronous } \\
\text { telehealth visit } \\
(n=194)\end{array}$ & p-value \\
\hline Age in years (mean +l- SD) & $49.7+/-18.9$ & $51.0+/-18.3$ & 0.46 (t-test) \\
\hline Gender (female) & $189(63.2 \%)$ & $119(61.3 \%)$ & $0.68(\mathrm{CS})$ \\
\hline $\begin{array}{l}\text { Insurance } \\
\text { Medicare } \\
\text { Commercial } \\
\text { Other government } \\
\text { Self pay }\end{array}$ & $\begin{array}{l}78(26.1 \%) \\
164(54.8 \%) \\
50(16.7 \%) \\
7(2.3 \%)\end{array}$ & $\begin{array}{l}56(28.9 \%) \\
95(49.0 \%) \\
36(18.6 \%) \\
7(3.6 \%)\end{array}$ & (CS) \\
\hline $\begin{array}{l}\text { Distance in miles } \\
\text { (median (range)) }\end{array}$ & $29.6(1.1-234)$ & 2 & $4(\mathrm{MW})$ \\
\hline Visit type (New) & $197(65.9 \%)$ & $95(49.0 \%)$ & $<0.0005(\mathrm{CS})$ \\
\hline $\begin{array}{l}\text { Diagnosis } \\
\text { Afferent } \\
\text { Efferent } \\
\text { Other }\end{array}$ & $\begin{array}{l}191(64.1 \%) \\
71(23.8 \%) \\
36(12.1 \%)\end{array}$ & $\begin{array}{l}110(56.7 \%) \\
59(30.4 \%) \\
25(12.9 \%)\end{array}$ & 0.219 (CS) \\
\hline
\end{tabular}

CS = Chi-Squared test; MW = Mann-Whitney U test 
Table E1: Comparison between unique patient encounters at Circle City Ophthalmology (provider KEL) between 2019 and 2020 (March 15-June 15)

\begin{tabular}{|c|c|c|c|}
\hline & $\begin{array}{l}2019 \\
(n=174)\end{array}$ & $\begin{array}{l}2020 \\
(n=140)\end{array}$ & p-value \\
\hline Age in years (mean $+l-$ SD) & $52.8+/-19.1$ & $52.5+/-18.6$ & $\mathrm{p}=0.88$ (T-test) \\
\hline Female gender (n (\%)) & $110(63.2 \%)$ & $81(57.9 \%)$ & $p=0.33(C S)$ \\
\hline $\begin{array}{l}\text { Distance in miles } \\
\text { (median, range) }\end{array}$ & $39(2.1-183)$ & $34(3.2-180)$ & $3(\mathrm{MW})$ \\
\hline $\begin{array}{l}\text { Insurance } \\
\text { Medicare } \\
\text { Commercial } \\
\text { Other government } \\
\text { Self-Pay }\end{array}$ & $\begin{array}{l}57(32.8 \%) \\
85(48.9 \%) \\
28(16.1 \%) \\
4(2.3 \%)\end{array}$ & $\begin{array}{l}35(25.0 \%) \\
101(72.1 \%) \\
3(2.1 \%) \\
1(0.7 \%)\end{array}$ & 005 (CS) \\
\hline $\begin{array}{l}\text { Visit type } \\
\text { New } \\
\text { Established } \\
\text { Study }\end{array}$ & $\begin{array}{l}110(63.2 \%) \\
64(36.8 \%) \\
0\end{array}$ & $\begin{array}{l}86(61.4 \%) \\
54(38.6 \%) \\
0(0 \%)\end{array}$ & $(\mathrm{CS})$ \\
\hline $\begin{array}{l}\text { Visit format } \\
\text { In-office } \\
\text { Video + audio } \\
\text { Audio only } \\
\text { Interprofessional }\end{array}$ & $\begin{array}{l}174(100 \%) \\
0 \\
0 \\
0\end{array}$ & $\begin{array}{l}112(80.0 \%) \\
22(15.7 \%) \\
2(1.4 \%) \\
4(2.9 \%)\end{array}$ & $P<0.0005(C S)$ \\
\hline $\begin{array}{l}\text { Diagnosis } \\
\text { Afferent } \\
\text { Efferent } \\
\text { Other }\end{array}$ & $\begin{array}{l}123(70.7 \%) \\
37(21.3 \%) \\
14(8.0 \%)\end{array}$ & $\begin{array}{l}84(60.0 \%) \\
49(35.0 \%) \\
7(5.0 \%)\end{array}$ & $\mathrm{p}=0.02(\mathrm{CS})$ \\
\hline
\end{tabular}

CS: Chi-Squared test; MW: Mann Whitney U test 
Table E2: Comparison between unique patient encounters at Indiana University (provider DDM (2019, 2020), MWK (2020)) between 2019 and 2020 (March 15-June 15)

\begin{tabular}{|c|c|c|c|}
\hline & $\begin{array}{l}2019 \\
(n=270)\end{array}$ & $\begin{array}{l}2020 \\
(n=171)\end{array}$ & p-value \\
\hline Age in years (mean $+/-$ SD) & $47.8+/-17.8$ & $45.3+/-18.1$ & $p=0.15$ (T-test) \\
\hline Female gender (n (\%)) & $182(67.4 \%)$ & $118(69.0 \%)$ & $\mathrm{p}=0.73(\mathrm{CS})$ \\
\hline $\begin{array}{l}\text { Distance in miles } \\
\text { (median, range) }\end{array}$ & $36(1.4-994)$ & $27(1.4-229)$ & $2(\mathrm{MW})$ \\
\hline $\begin{array}{l}\text { Insurance } \\
\text { Medicare } \\
\text { Commercial } \\
\text { Other government } \\
\text { Self-Pay }\end{array}$ & $\begin{array}{l}79(29.3 \%) \\
132(48.9 \%) \\
54(20.0 \%) \\
5(1.9 \%)\end{array}$ & $\begin{array}{l}37(21.6 \%) \\
82(48.0 \%) \\
41(24.0 \%) \\
11(6.4 \%)\end{array}$ & \\
\hline $\begin{array}{l}\text { Visit type } \\
\text { New } \\
\text { Established } \\
\text { Study }\end{array}$ & $\begin{array}{l}215(79.6 \%) \\
55(20.4 \%) \\
0\end{array}$ & $\begin{array}{l}0.2 \%) \\
.8 \%)\end{array}$ & $.02(\mathrm{CS})$ \\
\hline $\begin{array}{l}\text { Visit format } \\
\text { In-office } \\
\text { Video + audio } \\
\text { Audio only } \\
\text { Interprofessional }\end{array}$ & $\begin{array}{l}270(100 \%) \\
0 \\
0 \\
0\end{array}$ & $\begin{array}{l}115(67.3 \%) \\
47(27.5 \%) \\
9(5.3 \%) \\
0\end{array}$ & $\mathrm{P}<0.0005(\mathrm{CS})$ \\
\hline $\begin{array}{l}\text { Diagnosis } \\
\text { Afferent } \\
\text { Efferent } \\
\text { Other }\end{array}$ & $\begin{array}{l}155(57.4 \%) \\
39(14.4 \%) \\
76(28.1 \%)\end{array}$ & $\begin{array}{l}107(62.6 \%) \\
39(22.8 \%) \\
25(14.6 \%)\end{array}$ & $\mathrm{p}=0.002(\mathrm{CS})$ \\
\hline
\end{tabular}

CS: Chi-Squared test; MW: Mann Whitney U test 
Table E3: Comparison between unique patient encounters at Stanford Department of Ophthalmology (provider HEM) between 2019 and 2020 (March 15-June 15)

\begin{tabular}{|c|c|c|c|}
\hline & $\begin{array}{l}2019 \\
(n=226)\end{array}$ & $\begin{array}{l}2020 \\
(n=186)\end{array}$ & p-value \\
\hline Age in years (mean $+/-$ SD) & $54.2+/-19.4$ & $52.9+/-18.9$ & $p=0.48$ (T-test) \\
\hline Female gender (n (\%)) & $151(66.8 \%)$ & $111(59.7 \%)$ & $\mathrm{p}=0.13(\mathrm{CS})$ \\
\hline $\begin{array}{l}\text { Distance in miles } \\
\text { (median, range) }\end{array}$ & $29(1.2-2968)$ & $24(1-461)$ & $8(\mathrm{MW})$ \\
\hline $\begin{array}{l}\text { Insurance } \\
\text { Medicare } \\
\text { Commercial } \\
\text { Other government } \\
\text { Self-Pay }\end{array}$ & $\begin{array}{l}57(25.8 \%) \\
113(51.1 \%) \\
48(21.7 \%) \\
3(1.4 \%)\end{array}$ & $\begin{array}{l}63(33.9 \%) \\
79(42.5 \%) \\
42(22.6 \%) \\
2(1.1 \%)\end{array}$ & \\
\hline $\begin{array}{l}\text { Visit type } \\
\text { New } \\
\text { Established } \\
\text { Study }\end{array}$ & $\begin{array}{l}120(57.1 \%) \\
102(45.1 \%) \\
4(1.8 \%)\end{array}$ & $\begin{array}{l}90(48.4 \%) \\
96(51.6 \%) \\
0(0 \%)\end{array}$ & $p=0.10(C S)$ \\
\hline $\begin{array}{l}\text { Visit format } \\
\text { In-office } \\
\text { Video + audio } \\
\text { Audio only } \\
\text { Interprofessional }\end{array}$ & $\begin{array}{l}226(100 \%) \\
0 \\
0 \\
0\end{array}$ & $\begin{array}{l}72(38.7 \%) \\
110(59.1 \%) \\
4(2.2 \%) \\
0\end{array}$ & $\mathrm{P}<0.0005(\mathrm{CS})$ \\
\hline $\begin{array}{l}\text { Diagnosis } \\
\text { Afferent } \\
\text { Efferent } \\
\text { Other }\end{array}$ & $\begin{array}{l}139(61.8 \%) \\
61(27.1 \%) \\
25(11.1 \%)\end{array}$ & $\begin{array}{l}114(61.6 \%) \\
42(22.7 \%) \\
29(15.7 \%)\end{array}$ & $\mathrm{p}=0.30(\mathrm{CS})$ \\
\hline
\end{tabular}

CS: Chi-Squared test; MW: Mann Whitney U test 
Table E4: Comparison between unique patient encounters at Circle City Ophthalmology (provider KEL) 3/15/20-6/15/20 according to visit format.

\begin{tabular}{|c|c|c|c|}
\hline & $\begin{array}{l}\text { In-Office visit } \\
(n=112)\end{array}$ & $\begin{array}{l}\text { Synchronous } \\
\text { telehealth visit } \\
(n=24)\end{array}$ & p-value \\
\hline Age in years (mean $+/-$ SD) & $52.7+/-18.6$ & $53.4+/-15.1$ & 0.83 (t-test) \\
\hline Gender (female) & $65(58.0 \%)$ & $14(58.3 \%)$ & 0.98 (CS) \\
\hline $\begin{array}{l}\text { Insurance } \\
\text { Medicare } \\
\text { Commercial } \\
\text { Other government } \\
\text { Self pay }\end{array}$ & $\begin{array}{l}28(25.0 \%) \\
81(72.3 \%) \\
3(2.7 \%) \\
0\end{array}$ & $\begin{array}{l}6(25.0 \%) \\
17(70.8 \%) \\
0 \\
1(4.2 \%)\end{array}$ & $(\mathrm{CS})$ \\
\hline $\begin{array}{l}\text { Distance in miles } \\
\text { (median (range)) }\end{array}$ & $35(3.8-180)$ & 2 & $0.59(\mathrm{MW})$ \\
\hline Visit type (New) & $70(62.5 \%)$ & $12(50.0 \%)$ & $0.26(\mathrm{CS})$ \\
\hline $\begin{array}{l}\text { Diagnosis } \\
\text { Afferent } \\
\text { Efferent } \\
\text { Other }\end{array}$ & $\begin{array}{l}70(62.5 \%) \\
36(32.1 \%) \\
6(5.4 \%)\end{array}$ & $\begin{array}{l}10(41.7 \%) \\
13(54.2 \%) \\
1(4.2 \%)\end{array}$ & $0.12(\mathrm{CS})$ \\
\hline
\end{tabular}

CS: Chi-Squared test; MW: Mann Whitney $U$ test 
Table E5: Comparison between unique patient encounters at Indiana University (providers DDM, MWK) 3/15/20-6/15/20 according to visit format.

\begin{tabular}{|c|c|c|c|}
\hline & $\begin{array}{l}\text { In-Office visit } \\
(n=115)\end{array}$ & $\begin{array}{l}\text { Synchronous } \\
\text { telehealth visit } \\
(n=56)\end{array}$ & p-value \\
\hline Age in years (mean $+l-S D$ ) & $45.2+/-18.2$ & $45.3+/-18.1$ & 0.97 (t-test) \\
\hline Gender (female) & $83(72.2 \%)$ & $35(62.5 \%)$ & $0.20(\mathrm{CS})$ \\
\hline $\begin{array}{l}\text { Insurance } \\
\text { Medicare } \\
\text { Commercial } \\
\text { Other government } \\
\text { Self pay }\end{array}$ & $\begin{array}{l}24(20.9 \%) \\
56(48.7 \%) \\
29(25.2 \%) \\
6(5.2 \%)\end{array}$ & $\begin{array}{l}13(23.2 \%) \\
26(46.4 \%) \\
12(29.3 \%) \\
5(45.5 \%)\end{array}$ & $0.76(\mathrm{CS})$ \\
\hline $\begin{array}{l}\text { Distance in miles } \\
\text { (median (range)) }\end{array}$ & $24(2.4-185)$ & & $0.38(\mathrm{MW})$ \\
\hline Visit type (New) & $88(76.5 \%)$ & $32(57.1 \%)$ & 0.009 (CS) \\
\hline $\begin{array}{l}\text { Diagnosis } \\
\text { Afferent } \\
\text { Efferent } \\
\text { Other }\end{array}$ & $\begin{array}{l}77(67.0 \%) \\
19(16.5 \%) \\
19(16.5 \%)\end{array}$ & $\begin{array}{l}30(53.6 \%) \\
20(35.7 \%) \\
6(10.7 \%)\end{array}$ & $0.02(\mathrm{CS})$ \\
\hline
\end{tabular}

CS: Chi-Squared test; MW: Mann Whitney $U$ test 
Table E6: Comparison between unique patient encounters at Stanford University (provider HEM) 3/15/20-6/15/20 according to visit format.

\begin{tabular}{|c|c|c|c|}
\hline & $\begin{array}{l}\text { In-Office visit } \\
(n=72)\end{array}$ & $\begin{array}{l}\text { Synchronous } \\
\text { telehealth visit } \\
(n=114)\end{array}$ & p-value \\
\hline Age in years (mean $+/-$ SD) & $52.4+/-19.4$ & $53.3+/-18.6$ & 0.76 (t-test) \\
\hline Gender (female) & $41(46.9 \%)$ & $70(63.1 \%)$ & 0.55 (CS) \\
\hline $\begin{array}{l}\text { Insurance } \\
\text { Medicare } \\
\text { Commercial } \\
\text { Other government } \\
\text { Self pay }\end{array}$ & $\begin{array}{l}26(36.1 \%) \\
27(37.5 \%) \\
18(25.0 \%) \\
1(1.4 \%)\end{array}$ & $\begin{array}{l}37(32.5 \%) \\
52(45.6 \%) \\
24(21.1 \%) \\
1(0.9 \%)\end{array}$ & $0.74(\mathrm{CS})$ \\
\hline $\begin{array}{l}\text { Distance in miles } \\
\text { (median (range)) }\end{array}$ & $26(1.1-234)$ & 24 & $0(\mathrm{MW})$ \\
\hline Visit type (New) & $33(54.2 \%)$ & $51(44.7 \%)$ & 0.21 (CS) \\
\hline $\begin{array}{l}\text { Diagnosis } \\
\text { Afferent } \\
\text { Efferent } \\
\text { Other }\end{array}$ & $\begin{array}{l}44(62.0 \%) \\
16(22.5 \%) \\
11(15.5 \%)\end{array}$ & $\begin{array}{l}70(61.4 \%) \\
26(22.8 \%) \\
18(15.8 \%)\end{array}$ & 0.99 (CS) \\
\hline
\end{tabular}

CS: Chi-Squared test; MW: Mann Whitney $U$ test 


\section{Statement of Authorship}

Category 1:

a) Conception and design

K. E. Lai, H. E. Moss, and M. W. Ko

b) Acquisition of data

K. E. Lai, D. Chauhan, K. G. Gutierrez, and N. C. Villegas

C) Analysis and interpretation of data

H. E. Moss, K. E. Lai

Category 2:

a) Drafting the manuscript

K. E. Lai, H. E. Moss, M. W. Ko, D. D. Mackay

b) Revising it for intellectual content

H. E. Moss, M. W. Ko, D. D. Mackay, K. E. Lai

Category 3:

a) Final approval of the completed manuscript

H. E. Moss, M. W. Ko, D. D. Mackay, K. E. Lai 